\title{
Adipocyte iron regulates leptin and food intake
}

\author{
Yan Gao,, ${ }^{1,2}$ Zhonggang Li, ${ }^{1}$ J. Scott Gabrielsen, ${ }^{1}$ Judith A. Simcox, ${ }^{1}$ Soh-hyun Lee, ${ }^{1}$ Deborah Jones, ${ }^{1}$ Bob Cooksey, ${ }^{1,3}$ \\ Gregory Stoddard, ${ }^{4}$ William T. Cefalu, ${ }^{5}$ and Donald A. McClain ${ }^{2}$
}

'Departments of Medicine and Biochemistry, University of Utah, Salt Lake City, Utah, USA. ²enter on Diabetes, Obesity and Metabolism, Wake Forest University School of Medicine, Winston Salem,

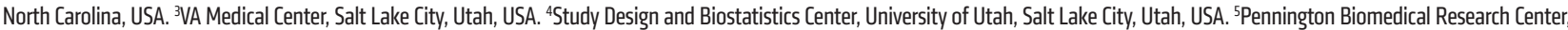
Louisiana State University System, Baton Rouge, Louisiana, USA.

Dietary iron supplementation is associated with increased appetite. Here, we investigated the effect of iron on the hormone leptin, which regulates food intake and energy homeostasis. Serum ferritin was negatively associated with serum leptin in a cohort of patients with metabolic syndrome. Moreover, the same inverse correlation was observed in mice fed a high-iron diet. Adipocyte-specific loss of the iron exporter ferroportin resulted in iron loading and decreased leptin, while decreased levels of hepcidin in a murine hereditary hemochromatosis $(\mathrm{HH})$ model increased adipocyte ferroportin expression, decreased adipocyte iron, and increased leptin. Treatment of 3T3-L1 adipocytes with iron decreased leptin mRNA in a dose-dependent manner. We found that iron negatively regulates leptin transcription via cAMP-responsive element binding protein activation (CREB activation) and identified 2 potential CREB-binding sites in the mouse leptin promoter region. Mutation of both sites completely blocked the effect of iron on promoter activity. ChIP analysis revealed that binding of phosphorylated CREB is enriched at these two sites in iron-treated 3T3-L1 adipocytes compared with untreated cells. Consistent with the changes in leptin, dietary iron content was also directly related to food intake, independently of weight. These findings indicate that levels of dietary iron play an important role in regulation of appetite and metabolism through CREB-dependent modulation of leptin expression.

\section{Introduction}

Iron deficiency is the most common nutrient deficiency in the United States (1). Individuals with iron deficiency have appetite loss, while dietary iron supplementation is associated with increased appetite in children $(2,3)$. The mechanism underlying these associations is poorly understood. Leptin, the protein product of the $o b$ gene, is a hormone that is secreted primarily by adipose tissue and is responsible for regulating feeding behavior (4-8). Dongiovanni et al. found that serum leptin is decreased in mice fed with $2 \%$ carbonyl iron diet, while this might be a secondary effect of fat-mass loss (9). There are, however, suggestions for a direct relationship between iron and leptin. Patients with $\beta$ thalassemia major, a condition usually accompanied by transfusional iron overload, fail to maintain adequate leptin production (10-12). Furthermore, the association between BMI and serum leptin levels is dampened or even abolished in these patients (13). Soluble transferrin receptor (sTfR), a clinical marker for total body iron stores, is negatively associated with serum leptin (14). Finally, serum ferritin, an iron storage protein and marker of both tissue iron stores and inflammation, is significantly correlated with appetite score and food intake (15). These studies demonstrate strong correlations among tissue iron stores, leptin, and feeding behavior. They do not, however, demonstrate causality nor mechanism for any of the relationships.

\section{Related Commentary: p. 3422}

Conflict of interest: The authors have declared that no conflict of interest exists. Submitted: March 11, 2015; Accepted: June 17, 2015.

Reference information: J Clin Invest. 2015;125(9):3681-3691. doi:10.1172/JCI81860.
We therefore investigated the effect of iron on leptin. We demonstrate in humans that the association between serum ferritin and leptin is independent of inflammation and that serum ferritin, even within its normal range, is among the best predictors of serum leptin. Studies in cell culture, mouse models, and humans demonstrate that iron plays a direct and causal role in determining leptin levels. Thus, the adipocyte responds to iron availability, as well as macronutrient status, to adjust expression of leptin, a major regulator of appetite, energy homeostasis, and metabolism.

\section{Results}

Human ferritin levels are inversely associated with serum leptin independently of inflammation and BMI. We examined the relationship of iron and leptin in a cohort of 76 individuals with $(n=36)$ and without $(n=40)$ diabetes recruited for an independent study of metabolic flexibility (16). Clinical characteristics of those individuals were shown in Supplemental Table 1; supplemental material available online with this article; doi:10.1172/JCI81860DS1. Ferritin was measured as an indicator of tissue iron stores. Ferritin is also an acute-phase response protein whose concentrations increase during inflammation and no longer reflect the level of iron stores. To mitigate the effects of inflammation and/or extreme iron overload and anemia, we restricted the analysis to individuals with normal serum ferritin (men $>30 \mathrm{ng} / \mathrm{ml}$ and $<300$ $\mathrm{ng} / \mathrm{ml}$; women $>15 \mathrm{ng} / \mathrm{ml}$ and $<200 \mathrm{ng} / \mathrm{ml})$ (17, 18). Excluding 12 individuals outside this range, we found a significant negative association between ferritin and leptin (Figure 1A, Pearson's $r=-0.527, P<0.0001)$. Serum ferritin is also negatively associated with serum leptin when individuals with abnormal ferritin are included, although the association is somewhat weaker (Pearson's 

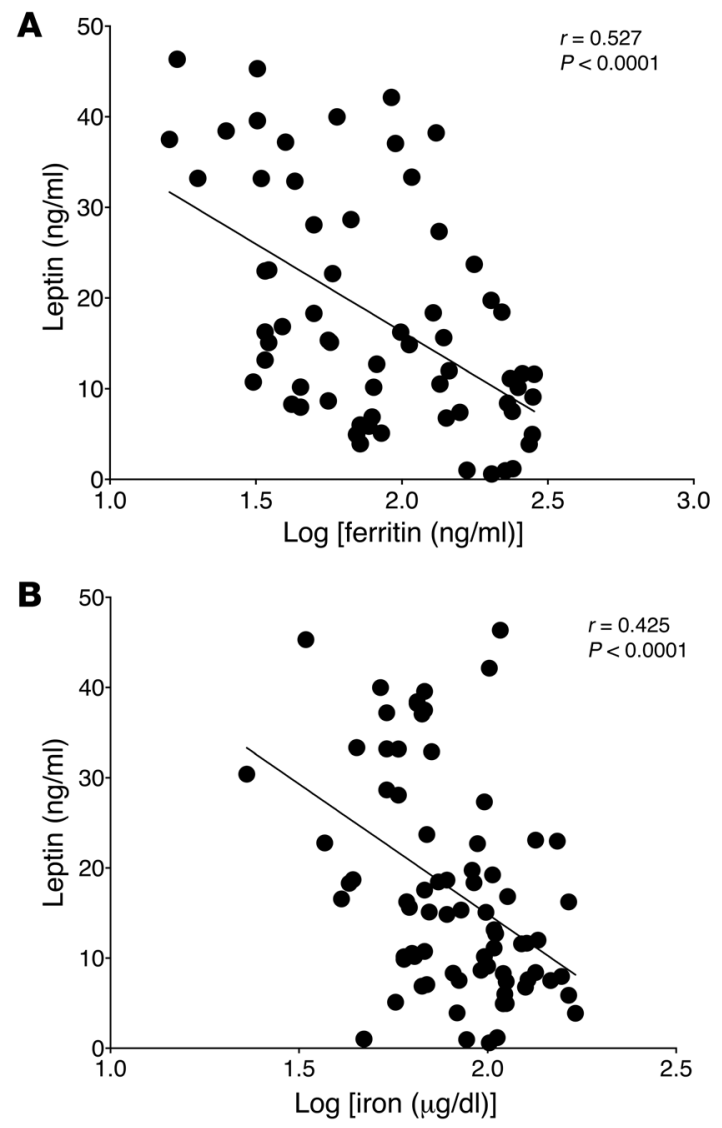

$r=-0.396, P=0.0004$, Supplemental Figure 1). Correcting for potential covariates, including an independent marker of inflammation (C-reactive protein, CRP), age, BMI, diabetes status, and sex had little effect on the ferritin-leptin association (Table 1 and Supplemental Table 2). Serum iron was also significantly negatively correlated with leptin (Pearson's $r=0.425, P<0.0001$, Figure $1 \mathrm{~B}$ ), and there is no association between ferritin and BMI in all subjects (data not shown).

Average ferritin values in women are significantly lower compared with men (average ferritin $77.07 \pm 12.38 \mathrm{ng} / \mathrm{ml}$ in women and $162.64 \pm 17.89 \mathrm{ng} / \mathrm{ml}$ in men, $\left.P=1.26 \times 10^{-4}\right)(19)$, and these lower ferritin levels are accompanied by higher leptin levels in women $(22.98 \pm 1.85 \mu \mathrm{g} / \mathrm{ml}$ in women vs. $9.41 \pm 1.27 \mu \mathrm{g} / \mathrm{ml}$ in men, $P=7.84$ $\left.\times 10^{-7}\right)$, despite their BMI values being equivalent $(31.56 \pm 1.21$ in women and $30.62 \pm 1.29$ in men).

Dietary iron overload increases adipocyte iron and decreases leptin $m R N A$ and serum protein levels in mice. Our previous studies have identified effects of iron on adiponectin and adipocyte metabolism $(20,21)$. We fed C57BL6/J male mice high- (2,000 $\mathrm{mg} / \mathrm{kg}$ ) and low normal-iron diets (35 mg/kg) for 2 months. The low normal-iron diets are derived from TestDiet AIN-93G recommended by the American Institute of Nutrition. The high-iron diet results in a modest
Figure 1. Serum ferritin and iron levels are inversely associated with serum leptin levels. (A) Serum leptin and ferritin levels were measured and correlated in a cohort of subjects with normal ferritin ( $n=64$, Pearson's $r=0.527, P<0.0001$ ). (B) Serum iron levels are inversely associated with serum leptin levels in a cohort of patients with type 2 diabetes, as well as in obese subjects with metabolic syndrome ( $n=76$, Pearson's $r=0.425, P<0.0001$ )

increase of liver iron (2-fold) which is within the 4-fold range seen in normal humans (22). To explore the regulation of adipocyte iron levels, we first measured the cytosolic iron in isolated adipocytes by ferrozine-based iron assay. We observed a $115 \%$ increase of iron in adipocytes from mice fed a high-iron diet compared with that in mice fed normal chow (low normal-iron diet) (Figure 2A, $P<0.05)$. We also demonstrated that adipocyte iron levels respond to dietary iron content in WT C57BL6/J mice by measuring mRNA levels of the transferrin receptor (Tfrc). Tfrc mRNA contains iron-response elements (IRE) in its 3' UTR that result in decreased Tfrc mRNA levels as cellular iron levels increase (23). We observed a 50\% decrease in Tfrc mRNA in adipose tissue from mice fed a high-iron diet compared with that in mice fed the low normal-iron chow (Figure 2B, $P<0.05$ ). Serum leptin decreased with dietary iron (Pearson's $r=0.26, P<0.01, n=36$ mice/group, Supplemental Figure 3). Serum leptin levels were $42 \%$ lower in mice on the high-iron diet compared with those on the low normal-iron diet (Figure 2C). Intracellular leptin levels assayed by Western blotting were 35\% lower (Figure 2, D and E), and leptin mRNA levels in epididymal pads were $41 \%$ lower in iron-overloaded mice (Figure $2 \mathrm{~F}$ ), mirroring the changes in serum leptin levels. To further confirm the effect of iron on leptin in intact animals, transgenic mice expressing the luciferase reporter gene under the control of leptin regulatory sequences were fed the low normal- or highiron diets. Fluorescence after i.p. injection with D-luciferin was 15\% lower in the mice on high-iron diets (Figure 2G). To avoid potential background from other tissues, isolated fat pads from different dietary iron-fed mice were lysed, and ex vivo measurements of luciferin bioluminescence were performed. Bioluminescence from high-iron-fed mice was lower than that from mice fed low normal-iron diets (Figure $2 \mathrm{H}$ ).

Deletion of adipocyte ferroportin results in increased adipocyte iron levels and decreased serum leptin. Previously, we have generated mice lacking the gene encoding the iron export channel fer-

Table 1. Multivariable linear regression analysis with leptin as the dependent variable and log (ferritin), BMI and sex as predictive variables in a cohort of patients with all the ferritin levels except those missing CRP values ( $n=70$ after excluding individuals without CRP data)

$\begin{array}{lccc}\text { Variables }^{A} & \text { Coefficient } & \text { SEM } & \boldsymbol{P}_{\text {values }} \\ \text { Log (Ferritin) } & -4.14 & 1.81 & 0.025 \\ \text { BMI } & 1.05 & 0.11 & <0.001 \\ \text { Sex } & -10.65 & 1.74 & <0.001\end{array}$

Multivariate logistic regression was analyzed by STATA. AThree other variables were considered for inclusion in multivariable linear regression model (shown in Supplemental Table 2), which then dropped out due to lack of statistical significance (diabetes, $P=0.218$; age, $P=0.468$; $\log (\mathrm{CRP}), P=0.418$ ) (Supplemental Table 2). 

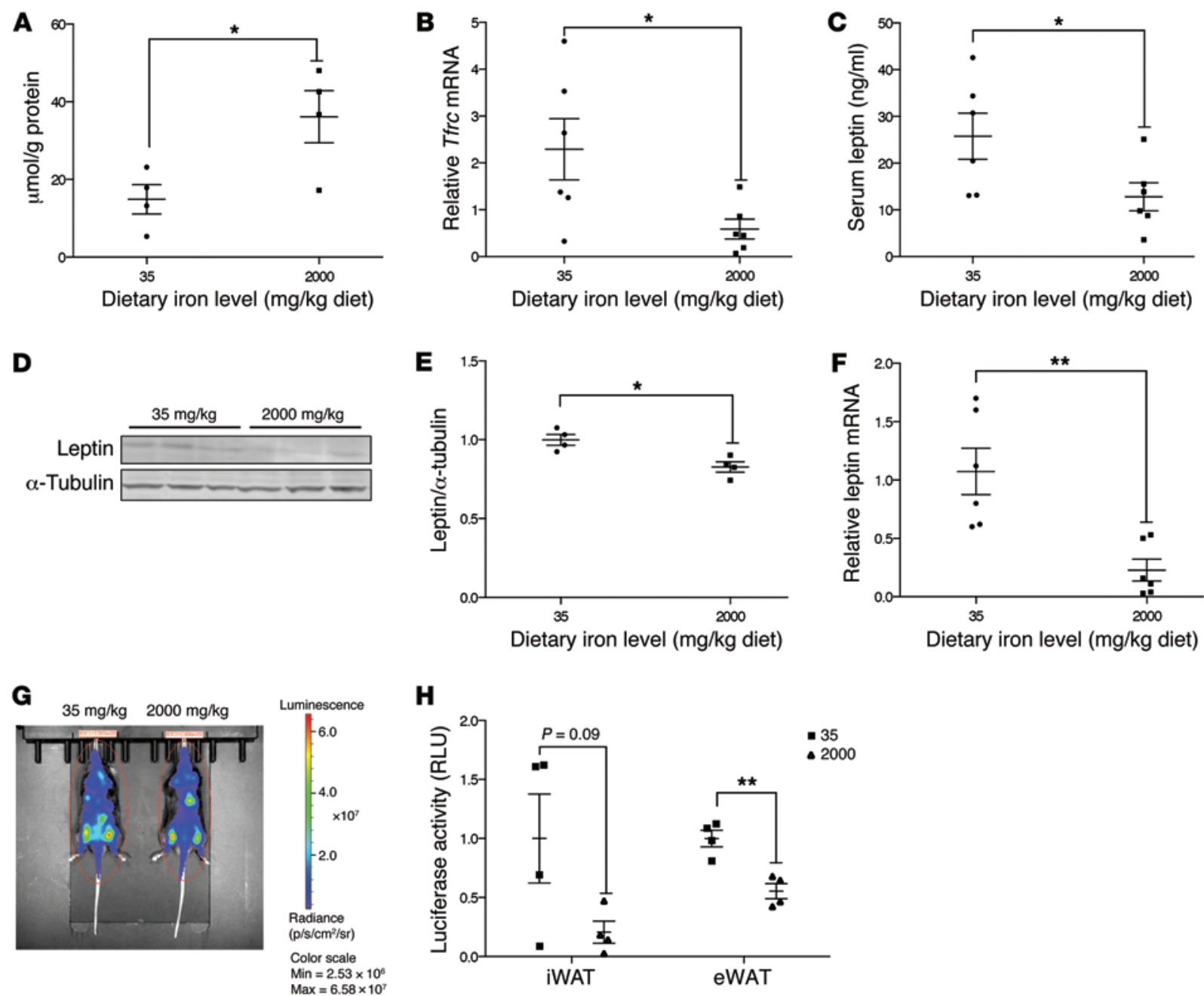

Figure 2. Serum leptin and adipocyte leptin mRNA levels decrease with dietary iron overload. (A) Iron levels measured by ferrozine-based colorimetric assay in mice fed low normal- and high-iron diet ( $n=4$ mice/group). (B) Tfrc mRNA levels quantified by qPCR and normalized to cyclophilin A in adipose tissue from mice fed different levels of dietary iron ( $n=6$ mice/group). (C) Serum leptin levels from the mice ( $n=6$ mice/group). (D) Intracellular leptin levels by Western blotting. Data are representative of 3 experiments with $n=4$ per replicate. (E) Quantification of leptin protein levels from $\mathbf{D}$ normalized to tubulin ( $n=4$ mice/group). (F) Leptin mRNA levels quantified by qPCR and normalized to cyclophilin A in adipose tissue from mice fed different dietary iron ( $n=6$ mice/group). (G and $\mathbf{H}$ ) Leptin expression is downregulated in live imaging (in vivo, $\mathbf{G}$ ) and in tissue lysate (ex vivo, $\mathbf{H})$ in high-iron-fed transgenic mice expressing the luciferase reporter gene under the control of leptin regulatory sequences. Data are representative of 3 experiments with $n=4$ per replicate. ${ }^{*} P<0.05$ and ${ }^{* *} P<0.01$ using 2 -tailed Student's $t$ tests. Data represent mean \pm SEM.

roportin $(F p n)$ in adipocytes. An Fpn $1^{A / f /}$ mouse, provided by Nancy C. Andrews (Duke University, Durham, North Carolina, USA) (24), was crossed to a mouse expressing Cre recombinase under control of the Ap2 promoter to obtain the adipocyte-specific Fpn KO mice (Ap2-Cre Fpn1 ${ }^{f / f l}$, herein referred to as aFpnKO) (25).

Fpn mRNA was undetectable in adipocytes purified by collagenase digestion from a $F p n \mathrm{KO}$ mice. Tfrc mRNA exhibited a decrease in isolated adipocytes of aFpnKO mice, indicating relative iron-overloading compared with WT mice (20). Namely, in a previous study of iron and adiponectin, we observed that splenic ferroportin expression was unaffected by Ap2-Cre (20). Because splenic ferroportin reflects macrophage expression almost exclusively, that result clearly indicates that the macrophage ferroportin expression was not affected by expression of $\mathrm{Ap} 2$ - $\mathrm{Cr}$, wherein the product of the Ap2 gene, FABP4, is expressed at approximately 10,000-fold lower levels than in adipocytes (26). This is consistent with other studies that have used the ap 2 promoter and achieved fat-specific expression with documented lack of effects on macrophage expression $(27,28)$. The increased levels of adipocyte iron in the aFpnKO mice resulted in a $49 \%$ decrease in levels of serum leptin (Figure 3A, $P<0.05$ ). There was no change in body weight or body composition, as analyzed by a Magnetic Resonance Imaging (MiniSpec, Bruker) (Figure 3B).

Lower adipocyte iron is associated with higher serum leptin in hereditary hemochromatosis. If iron decreases leptin secretion, we would expect high leptin levels in models of decreased adipocyte iron. $\mathrm{Hfe}^{-/-}$mice are a model of human hereditary hemochromatosis $(\mathrm{HH})$, a disease of genetic iron overload wherein the gene most commonly mutated in $\mathrm{HH}$ has been deleted. HFE protein is required for normal regulation of a master iron regulatory hormone, hepcidin, which downregulates the iron export channel ferroportin $(29,30)$. HH or Hfe deletion results in low hepcidin, 

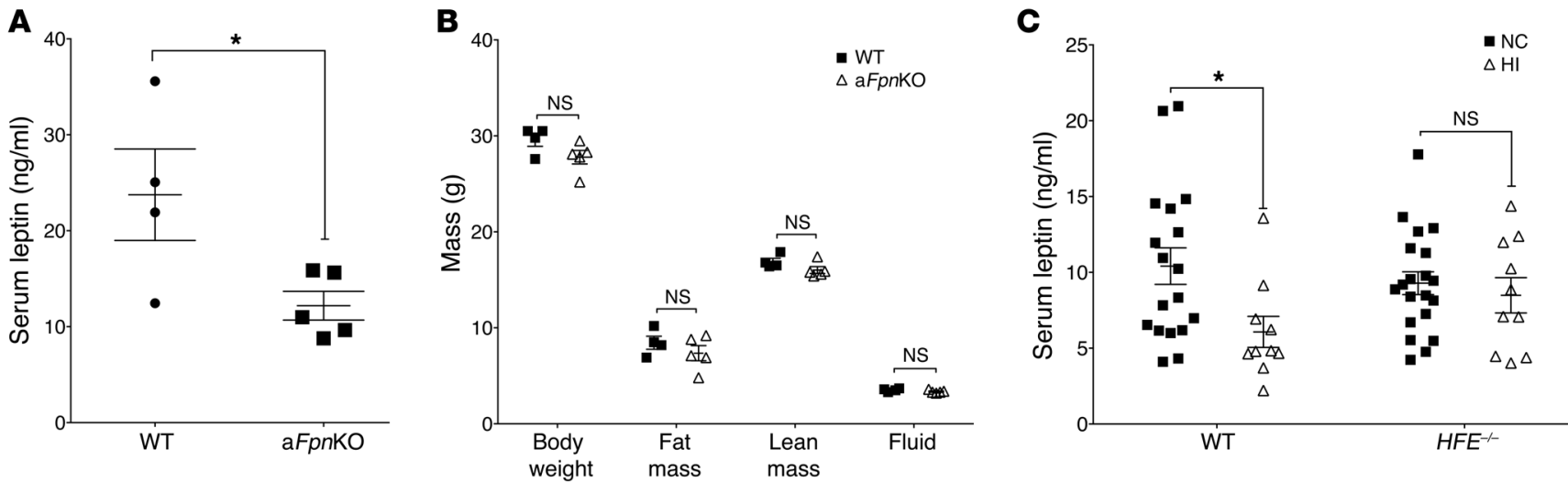

Figure 3. Serum leptin levels in mouse models with increased and decreased adipocyte iron. (A) Decreased serum leptin levels in aFpnKO ( $n=4$ or 5 mice/group). (B) Body composition in aFpnKO compared with WT mice ( $n=4$ or 5 mice/group). (C) Serum leptin in WT and HFE ${ }^{-/-}$mice on the 129/ SvEvTac background fed normal chow $(330 \mathrm{mg} / \mathrm{kg})$ and high-iron $(20 \mathrm{~g} / \mathrm{kg})$ diets $\left(n=10-20\right.$ mice/group). ${ }^{*} P<0.05$ using 2 -tailed Student's $t$ tests. Data represent mean $\pm \mathrm{SEM}$.

increased ferroportin expression, and increased iron egress from cells that express ferroportin, such as duodenal enterocytes. Adipocytes also express ferroportin , as demonstrated previously by us, and are therefore paradoxically iron under-loaded in this disease of overall iron overload (20). $\mathrm{Hfe}^{-/-}$mice therefore have less iron in adipocytes, and we determined that this results in higher serum leptin compared with littermate WT mice (Figure 3C).

Iron decreases leptin transcription and activates CREB. To demonstrate that the decreased leptin mRNA levels are due to decreased transcription and that iron regulates leptin directly, we examined the effects of iron on leptin in a cell culture model. We observed a decrease of leptin after treatment with ferric ammonium citrate (FAC) in both primary mouse adipocytes isolated from inguinal white adipose tissue (iWAT) and progenitor cells isolated by FACS and differentiated in vitro (Figure 4A and Supplemental Figure 4A). 3T3-L1 adipocytes, derived from a commercial cell line 3T3-L1 preadipocytes (ATCC), differentiated with isobutylmethylxanthine/dexamethasone/insulin express very little leptin transcript; however, when they were differentiated in the presence of a PPAR $\gamma$ agonist, ciglitazone, the adipocytes have been shown to exhibit a 5-fold increase in leptin mRNA and maintain insulin sensitivity and their differentiated phenotype (31). Similarly to primary adipocyte culture, we observed decreased intracellular leptin protein levels measured by Western blotting after FAC treatment (Figure 4, B and C; see complete unedited blots in the Supplemental Material). Secreted leptin in the medium decreased $36 \%$ with iron treatment (Figure $4 \mathrm{D}, P<0.05$ ), which was reversed by an iron chelator, deferoxamine (DFO). Similarly, leptin mRNA levels also decreased $48 \%$ with iron treatment, and DFO treatment abolished the iron-induced decrease of leptin mRNA, while DFO itself also blunted leptin expression significantly (Figure 4, $\mathrm{D}$ and $\mathrm{E}$ ). The U-shaped curve may represent a nonphysiologic effect of extremely low iron levels, perhaps reflecting undermetallation of components normally required for nutrient sensing and/ or leptin synthesis. The decrease in leptin by FAC treatment was dose dependent (Figure 4F, $r=0.668, P<0.01$ ). The levels of iron used in treating the cultured adipocytes have been shown to have no cytotoxic effect and cause a dose-dependent decrease in the expression of Tfrc in parallel with the increase of intracellular iron measured by ferrozine-based iron assay (ref. 20 and Supplemental Figure 5, A and B), indicating that the resulting intracellular iron levels are in a physiologically sensed range. Adipocytes from mice fed the high-iron diet had iron levels $(36.1 \pm 6.0 \mu \mathrm{mol} / \mathrm{g}$ protein $)$ comparable to those of the cultured cells treated with the highest $(200 \mu \mathrm{g} / \mathrm{ml})$ dose of FAC $(36.6 \pm 2.9 \mu \mathrm{mol} / \mathrm{g}$ protein) (Figure $2 \mathrm{~A}$ and Supplemental Figure 5C). Cells treated with transferrin-bound iron (Holo-TF) also showed decreased leptin expression compared with cells treated with unbound transferrin (Apo-TF) (Supplemental Figure 4B). Moreover, treatment of adipocytes with the antioxidant n-acetylcysteine (NAC) had no effect on downregulation of leptin by iron, suggesting FAC may repress leptin in an oxidant stress-independent manner in adipocytes.

Iron can regulate mRNA levels posttranscriptionally by IRE and iron-responsive proteins (IRP). Binding of IRP to IRE in the 3'-UTR of mRNA typically increases mRNA stability, while binding of IRP to the 5'-UTR typically decreases translation. Binding of free iron to IRP causes their dissociation from the mRNA and either enhanced mRNA degradation ( $3^{\prime}$-IRE) or enhanced translation (5'-IRE). Leptin mRNA possesses a 59-bp 5'-UTR and 2.7-kb 3'-UTR. We transfected 3T3-L1 adipocytes with constructs containing luciferase with each or both UTRs and found no effect of iron on luciferase activity, indicating leptin is not an IRE-IRP targeted gene (Supplemental Figure 6). Iron also did not decrease the half-life of the endogenous mRNA measured after actinomycin D treatment of cells (data not shown).

We next constructed 2 luciferase reporter plasmids with the proximal 5,986 bp and $764 \mathrm{bp}$ of the murine leptin promoter. We first measured luciferase activity driven by the proximal $764 \mathrm{bp}$ of the murine leptin promoter, a region that contains sites known to regulate leptin transcription, including CCAAT/enhancer binding protein $(\mathrm{C} / \mathrm{EBP})$, specificity protein 1 (SP1), and the hypoxia response element (HRE). Iron did not decrease the activity of this proximal promoter (Supplemental Figure 7). Luciferase activity driven by 5,986 bp leptin promoter, however, decreased 33\% after FAC treatment of the cells (Figure $5 \mathrm{~A}$ ). We found that this region, as well as the human leptin promoter (32), contains potential cAMP- 
A

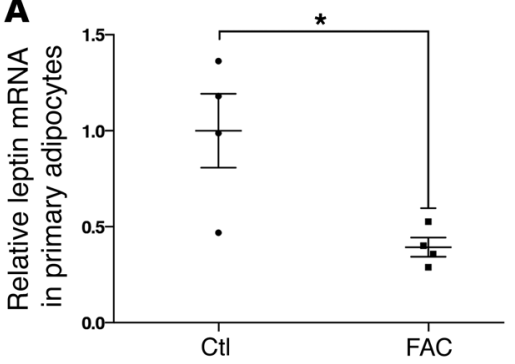

D

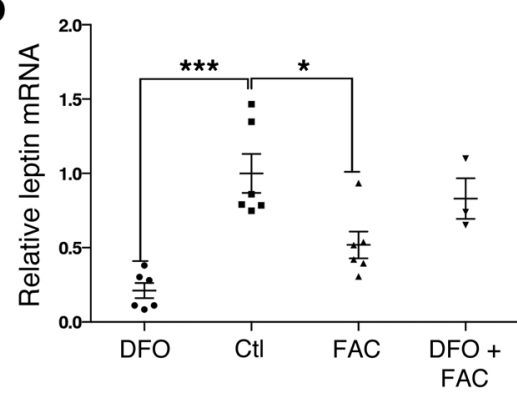

B

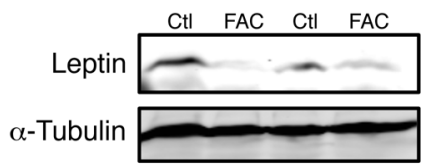

C

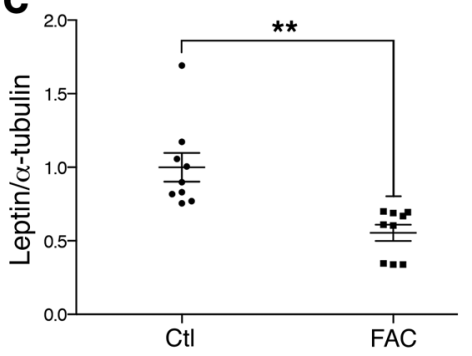

E

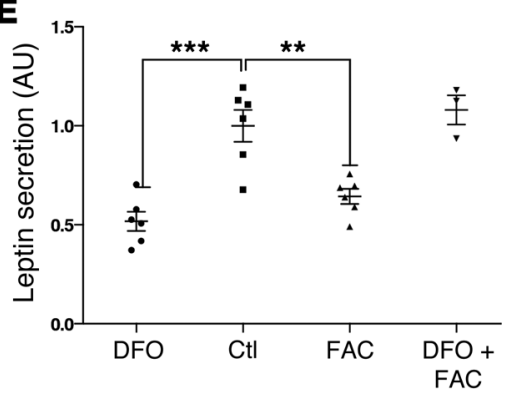

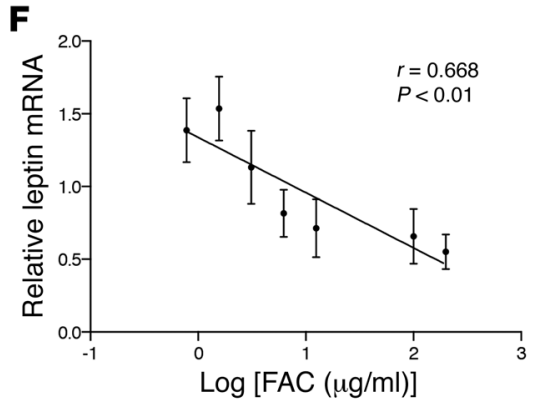

Figure 4. Leptin mRNA and protein levels decrease with iron treatment in primary adipocytes or 3T3-L1 adipocytes. (A) Leptin mRNA levels decrease in collagenased floating primary adipocytes treated with FAC $(n=4)$. (B) Intracellular leptin protein decreases with FAC treatment. Data are representative of 3 experiments with $n=3$ per replicate. (C) Quantification of Western blots normalized to $\alpha$-tubulin $(n=9)$. (D and E) Leptin secreted mRNA (D) and protein (E) levels in 3T3-L1 cells following 6-hour treatment with FAC $(25 \mu \mathrm{g} / \mathrm{ml})$, iron chelator desferoxamine (DFO, $100 \mu \mathrm{M})$, and FAC (25 $\mu \mathrm{g} / \mathrm{ml})$ plus DFO (100 $\mu \mathrm{M})(n=3$ or 6$)$. (F) Dose response for suppression of leptin mRNA by iron $(n=3$, Pearson's $r=0.668, P<0.01)$. ${ }^{*} P<0.05$, ${ }^{* *} P<0.01$, and ${ }^{* * *} P<0.001$ using 2-tailed Student's $t$ tests (A, C-E). Data represent mean \pm SEM.

response elements (CRE), as predicted from the transcriptional database of GenBank (http://www.ncbi.nlm.nih.gov/genbank/). We therefore investigated the effect of iron on CRE binding protein activation (CREB activation). FAC treatment resulted in increased phosphorylation of CREB and no difference in total protein levels (Figure 5, B and C; see complete unedited blots in the Supplemental Material). Consistent with the increased phosphorylation of CREB, we also observed increased expression of a downstream target of CREB activation, PGC1 $\alpha$ (Supplemental Figure 8A). Increased CREB phosphorylation in iron-treated cells occurred independently of 2 of its known activators, cAMP and calcium, with FAC treatment actually decreasing both of them (Supplemental Figure 9). A membrane-permeable cAMP analogue (8-Br-cAMP) activates a known CREB kinase, cyclic AMP-dependent protein kinase. Treatment of 3T3-L1 adipocytes with 8-Br-cAMP or the adenylyl cyclase activator forskolin decreased luciferase activity and abolished iron's effect on expression of the 5,986-bp luciferase construct (Figure 5, $\mathrm{D}$ and E). 8-Br-cAMP treatment also decreased leptin transcript levels (Supplemental Figure 8B) but did not affect iron metabolism in terms of Tfrc expression (Supplemental Figure 8C). We generated 3T3-L1 cells stably expressing a dominant-negative CREB inhibitor, ACREB, a synthetic polypeptide that heterodimerizes with and disrupts binding of CREB1, CREM, and ATF1, but not unrelated bZIP proteins to DNA (33). In cells expressing ACREB, iron lost its effect on downregulation of the 5,986-bp promoter luciferase activity, confirming that functional CREB sites confer iron-responsiveness to the promoter (Figure $5 \mathrm{~F}$ ).

Iron increases CREB occupancy of the leptin promoter. We mutated 3 potential CREB sites in each of 2 5,986-bp plasmids (plasmids 425 and 533, Supplemental Figure 10A). Iron lost its ability to decrease luciferase activity in 3T3-L1 adipocytes stably expressing plasmid 533 but not in cells expressing WT or 425 plasmids (Figure 6A). Plasmid 533 contains 2 potential CRE sites and one typical AP-1: CRE-like site, from -2590 bp to-2,583 bp (CRE-1, CTACTTCA); from -2,080 bp to -2,073 bp (CRE-2, CTATGTCA); and from -877 bp to -883 bp (AP-1: CRE-like, TTAGTCA) (Supplemental Figure 10B). AP-1 and CRE proteins recognize a similar DNA sequence, and there is evidence that the FOS/JUN (components of AP-1) complex and CREB families are able to dimerize and bind to AP-1/CRE-like sequences, allowing crosstalk between the 2 signaling systems (34-36). Such degenerate CRE sites can be functional, as shown in other systems (37-39). We performed EMSA on the CRE-1, CRE-2, and AP-1/CRE-like sites. Three oligonucleotide probes containing the CRE-1, CRE-2, and AP-1/CRElike sequences were synthesized and biotinylated. Both biotinlabeled CRE- 1 and CRE- 2 formed a complex with nuclear extracts (Figure 6, B and C). Coincubation with a 200-fold excess of a non-biotin-labeled CRE-1 or CRE-2 oligonucleotide effectively abolished complex formation. A mutated oligonucleotide in which the potential CRE-1 binding sequence (CTACTTCA) was mutated to mCRE-1 (CTAAATCA) failed to compete for binding with the biotin-labeled CRE-1 probe (Figure 6B). Similarly, mutation of the potential CRE-2 site (TATGTCA) to mCRE-2 (TATGTCA) resulted in failure to compete for the binding of biotin-CRE-2 to nuclear protein (Figure 6C). We did not observe any band shifts of biotin-labeled AP-1 oligonucleotides after incubation with 3T3L1 nuclear extracts (Supplemental Figure 11). Nuclear protein extracted from FAC-treated adipocytes showed increased pro- 

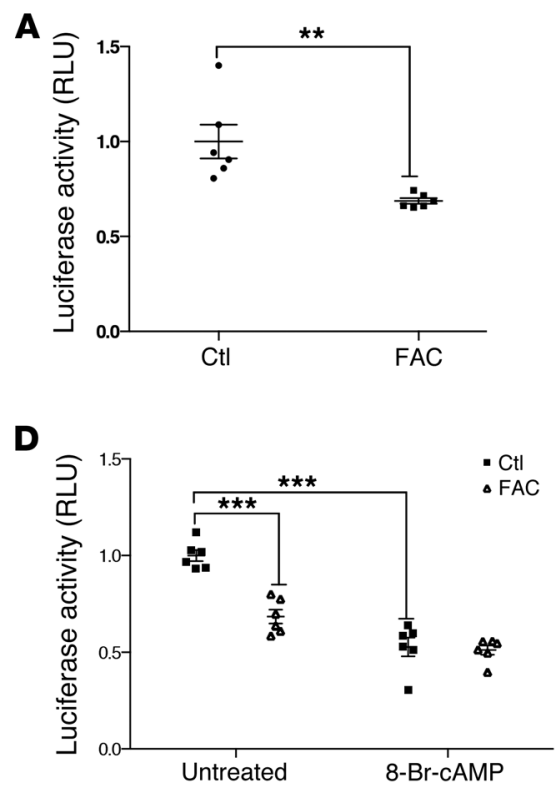

B

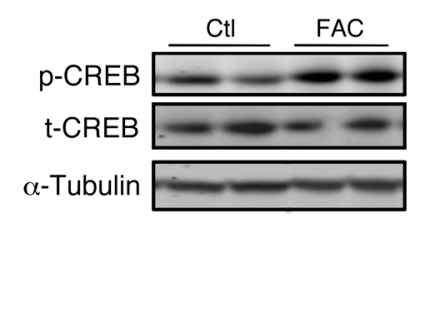

C

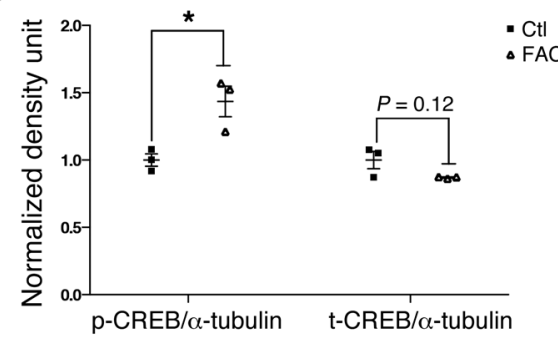

$\mathbf{F}$

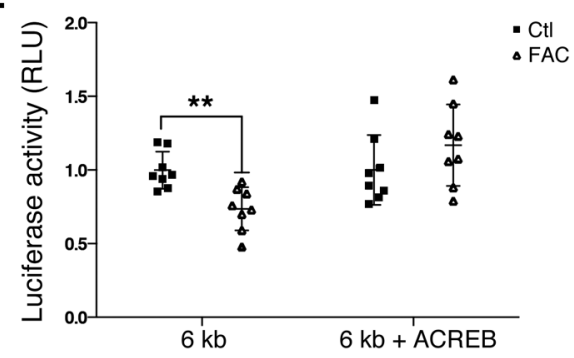

Figure 5. Iron decreases leptin promoter activity and activates CREB. (A) Distal leptin promoter-driven luciferase activity (-5986 bp) in the presence or absence of $100 \mu \mathrm{g} / \mathrm{ml} \mathrm{FAC}(n=6)$. (B) Western blot for p-CREB, total CREB (t-CREB), and $\alpha$-tubulin in 3T3-L1 adipocytes treated with $100 \mu \mathrm{g} / \mathrm{ml} \mathrm{FAC} \mathrm{for}$ 24 hours. Data are representative of 3 experiments with $n=3$ per replicate. (C) Quantitation of Western blots normalized to $\alpha$-tubulin ( $n=3$ ). (D) Distal leptin promoter luciferase activity in 3T3-L1 adipocytes treated with CAMP agonist, 8-Br-CAMP (1 mM), and/or $100 \mu \mathrm{g} / \mathrm{ml} \mathrm{FAC} \mathrm{for} 24 \mathrm{hours}(n=6)$. (E) Distal leptin promoter luciferase activity in 3T3-L1 adipocytes treated with cAMP agonist, forskolin ( $2 \mu \mathrm{M})$ and/or $100 \mu \mathrm{g} / \mathrm{ml} \mathrm{FAC} \mathrm{for} 24$ hours ( $n=5$ or 6$)$. (F) ACREB abolished the iron-mediated decrease of luciferase activity driven by the distal leptin promoter construct $(n=8)$. ${ }^{*} P<0.05$, ${ }^{* *} P<0.01$, and ${ }^{* * *} P<0.001$ using 2-tailed Student's $t$ tests (A and $\mathbf{C}-\mathbf{F}$ ). Data represent mean \pm SEM.

tein-probe interaction compared with the control group (Figure 6D). These findings indicate that the CRE- 1 and -2 sequences in the leptin promoter are functional binding sites. We next measured CREB occupancy at those 2 potential CRE sites using ChIP. As predicted by CREB phosphorylation status, cells treated with iron exhibited a 3- to 4-fold increase in occupancy by phosphorylated CREB (p-CREB) sites $(P<0.01$, Figure $6 \mathrm{E})$.

Iron-induced downregulation of leptin is associated with increased food intake. To demonstrate that iron-induced changes in leptin are physiologically significant, we studied the effects of chows with different dietary iron content on serum leptin and food intake in mice. We fed C57BL6/J male mice high-, high normal- (500 mg/kg), low normal-, or low-iron diets $(4 \mathrm{mg} / \mathrm{kg}$ ) for 2 months. The high normal-iron diet is representative of standardized diets in animal facilities, which range from $200-500 \mathrm{mg} / \mathrm{kg}$ iron. Mice were studied in metabolic chambers with monitoring of food intake after 9-12 weeks on the diets. We observed a positive correlation of dietary iron levels and food consumption (Figure 7A, Pearson's $r=0.24, P<0.001)$. Mice on the high-iron diet tend to eat more during each 15 -minute interval in the chamber during 3 days (Figure $7 \mathrm{~B}, P<0.0001$ ), and accumulated food intake is higher in high-iron diet compared with low-iron diet (Figure 7C, $P<0.0001)$. Body weights did not change with different dietary iron after 9 weeks on diet (low-iron, $28.88 \pm 0.31 \mathrm{~g}$; low normal chow, $29.55 \pm 0.33 \mathrm{~g}$; high normal-iron, $28.26 \pm 0.37 \mathrm{~g}$; high-iron, $28.76 \pm 0.30 \mathrm{~g}$; linear regression, $P=0.104, n=36$ mice/group, Supplemental Figure 12). To demonstrate that the change of feeding behavior under different levels of dietary iron is mediated through changes in leptin levels, we fed the same diets to $o b / o b$ mice, where the leptin gene is mutated and nonfunctional. In $o b / o b$ mice, the association of dietary iron level with food intake is abolished (Figure 7D). Similarly, no difference in food intake was apparent comparing mice on the high-iron diet to those on the low normal-iron diet in ob/ob mice (Figure 7, E and F).

\section{Discussion}

Iron is an essential constituent of many macromolecules involved in cell metabolism and is required for survival and proliferation. At the same time, iron can act as a potent and potentially dangerous oxidant. Iron levels are therefore highly regulated at the levels of uptake, storage, and recycling in the whole organism, as well as in individual tissues and cells. A typical adult has total body iron stores of approximately 1-3 g. A balance between dietary uptake and tissue loss is usually maintained in healthy humans, wherein 1-3 mg daily losses through bleeding and sloughing of cells from skin and mucosal surfaces is balanced by gastrointestinal uptake $(40,41)$. However, there is no defined physiological means of active iron excretion, so the levels of tissue iron can increase over time with dietary excess, such that normal levels of serum ferritin, a marker of tissue iron stores in otherwise healthy individuals, vary 15 - to 20 -fold. We have previously hypothesized that the central role of iron in metabolism dictates that its availability should be reflected in the metabolic state of the organism, and that cells that regulate metabolism - such as adipocytes - therefore need to sense not only the macronutrient status of the organism, but also the availability of iron to support fuel oxidation. This hypothesis is supported by the regulation of adiponectin by iron (20). Recent studies have also noted an association between serum ferritin, sTfR, and leptin, the adipocyte-specific satiety hormone $(14,15)$. In this paper, we have verified that serum ferritin levels, reflecting 


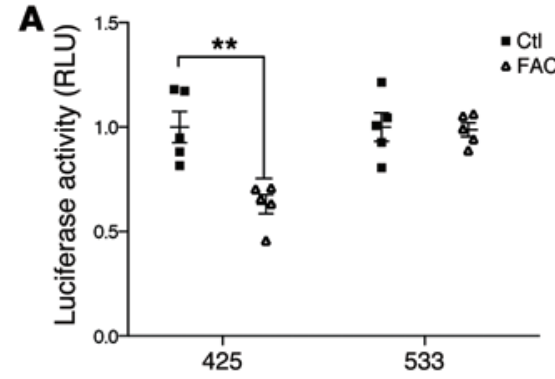

C

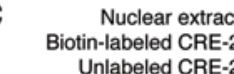
otin-labeled CRE-2 +++++ Unlabeled mutant CRE-2 $\quad-\quad-\quad+$

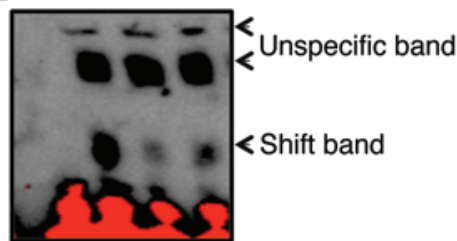

E

응

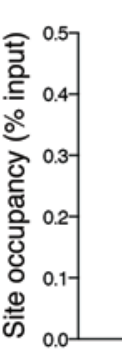

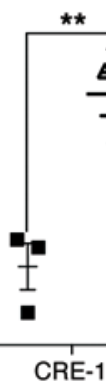

B Nuclear extract -+++ Biotin-labeled CRE-1 ++++ Unlabeled mutant CRE-1 $-{ }_{-}+-$

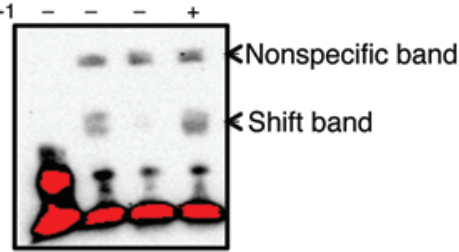

D

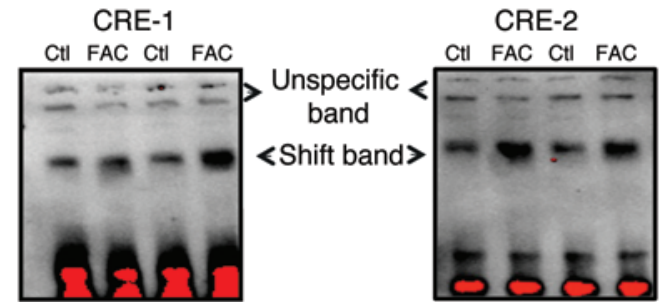

Figure 6. Iron decreases leptin promoter activity via potential CRE binding sites. (A) Iron decreases promoter activity in control and the 425 mutant construct, but not the 533 mutant construct $(n=5)$. (B) EMSA with the CRE-1 oligos, as indicated. Unlabeled CRE-1 abolished protein-probe complex formation, and mutation of the CRE-1 failed to compete the protein-probe interaction. (C) EMSA with the CRE-2 oligos, as indicated. Unlabeled CRE-2 abolished protein-probe complex formation, and mutation of the CRE-2 failed to compete the protein-probe interaction. (D) Nuclear extracts from FAC-treated 3T3-L1 adipocytes had increased protein-probe interaction compared with control group. (E) p-CREB (S133) occupancy at leptin promoter sites was induced by iron. qPCR amplification of DNA sequences flanking CRE-1 and CRE-2 sites from ChIPs performed with p-CREB (S133) antibody ( $n=3)$. ${ }^{* *} P<0.01$ using Student's $t$ tests ( $\mathbf{A}$ and $\mathbf{E}$ ). Data of figure $\mathbf{B}-\mathbf{D}$ are representative of 3 experiments with $n=3$ per replicate. Data represent mean \pm SEM.

tissue iron stores, are among the best predictors of serum leptin under physiological conditions. We have demonstrated this in humans, in cultured cells, and by manipulation of iron stores and adipocyte iron levels in rodents. More importantly, the relationship is causal, reflecting regulation of leptin transcription by iron. Leptin is causally linked to feeding behavior (42), and consistent with this, the changes in leptin in response to iron are accompanied by changes in food intake.

The regulation of leptin by iron is operative across physiologic and pathophysiologic iron levels. The current report demonstrates regulation across the range of normal human serum ferritin values. BMI is well known to be positively correlated with serum leptin (43), and consistent with this, we found serum leptin in the obese subjects (upper 25th percentile BMI) to be 3.7-fold higher than that in the lean subjects (lower 25th percentile BMI) (Supplemental Figure 2A). At the same time, we found that serum leptin in the low-iron subjects (lower 25th percentile ferritin) was 3.2-fold higher than that in the high-iron subjects (higher 25th percentile ferritin) (Supplemental Figure 2B), indicating ferritin is also a good clinical predictor of leptin. Our results suggest that this may be a direct result of adipocyte iron loading, even within the physiologic range. In the mouse studies, as we have previously reported, the low normal- and high normal-iron diets represent the range of iron content seen in normal chows, and the high-iron diet does not cause overt iron pathology and results in increases in hepatic iron within the ranges seen in normal humans (44). Likewise, in the cell culture models, addition of iron to cells results in modulation of the transferrin receptor in a manner that mirrors normal iron physiology (Figure 2A and Supplemental Figure 5C). Thus, we think the ranges of iron represented in these model systems reflect the variation seen in normal humans, and leptin is regulated throughout these ranges of iron.

Although we did not study humans with overt iron deficiency or overload, previous reports are consistent with the current results and demonstrate that the association of leptin and iron is also maintained in pathophysiologic states. Leptin levels are lower $(11,12,14)$, and the normal positive relationship between BMI and leptin is lost in males suffering from thalassemia major, a condition in which transfusional iron overload develops (13). Leptin levels remain low in those thalassemic patients, even at high BMI. 
A

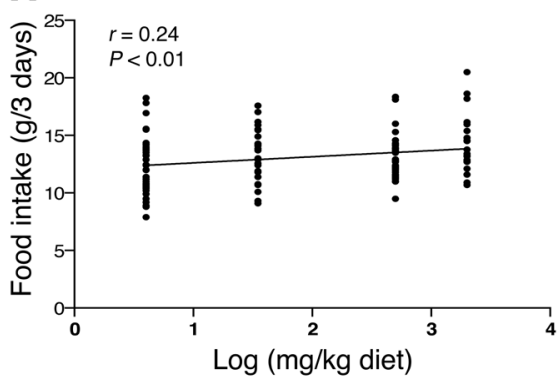

D

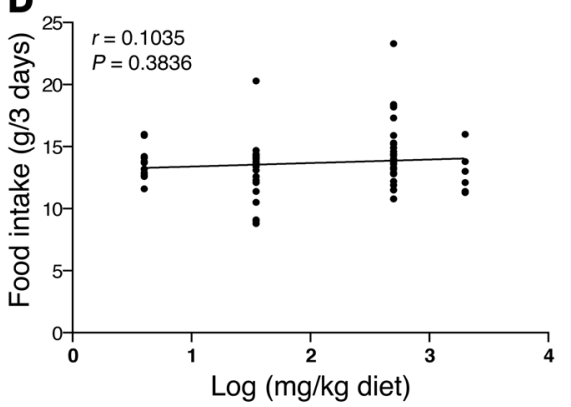

B

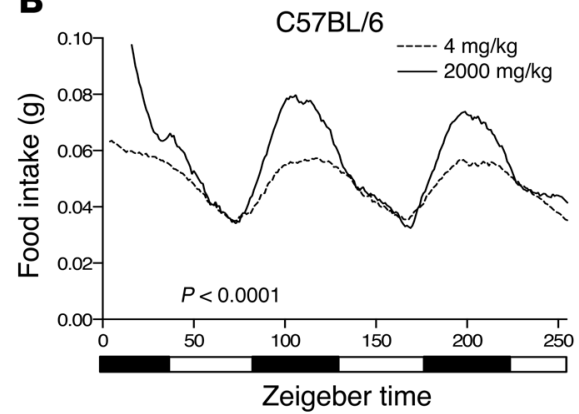

E

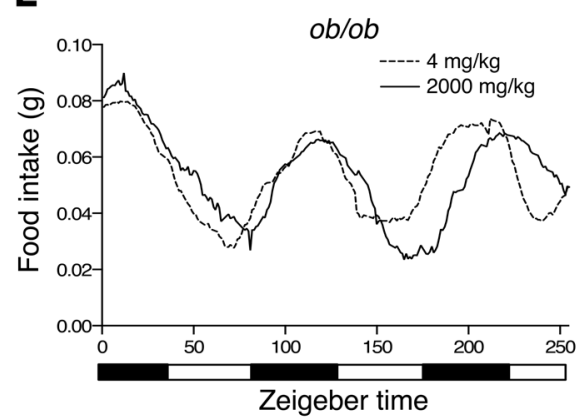

C

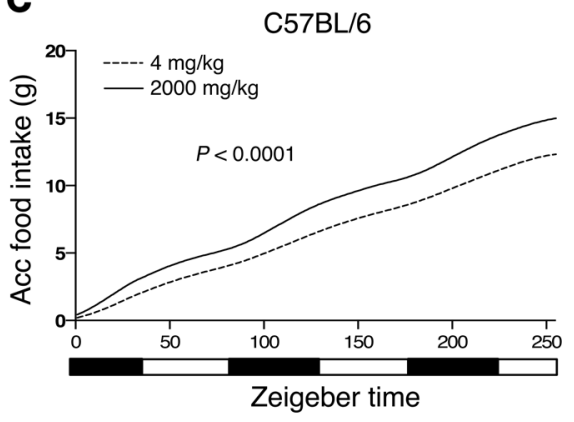

$\mathbf{F}$

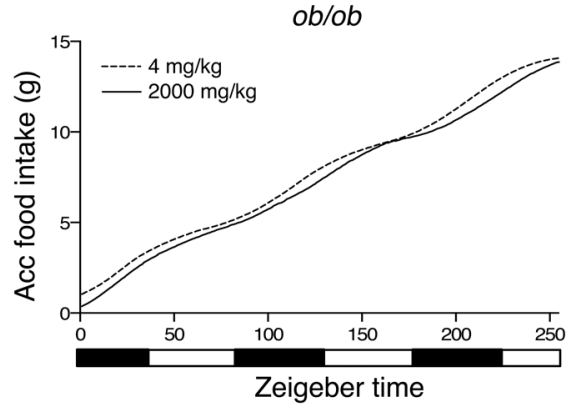

Figure 7. Decreased leptin in mice fed different levels of dietary iron is associated with increased food intake. (A) Food intake is positively associated with dietary iron levels in mice ( $n=69$ mice/group, Pearson's $r=0.24, P<0.01)$. (B and C) Real-time recording (B) and accumulation of food intake (C) in mice on low- ( $n=19$ mice/group) and high-iron diets ( $n=12$ mice/group) (Student's $t$ test, $P<0.0001$ for food intake and accumulated food intake). Black bar in zeitgeber time is nighttime ( $12 \mathrm{~h}$ daily) and white bar is daytime ( $12 \mathrm{~h}$ daily). (D) Dietary iron association with food intake is abolished in ob/ob mice $(n=73$ mice/group, Pearson's $r=0.10, P=0.38$ ). ( $(E$ and $\mathbf{F}$ ) Real-time recording and accumulation of food intake in $o b / o b$ mice with different diet. $o b / o b$ mice fed with high-iron diet ( $n=6$ mice/group) had no difference in food intake compared with low-iron diet ( $n=13$ mice/group) in both real-time (E) and accumulated food intake (F). $P<0.0001$ using 2-tailed Student's $t$ tests $(\mathbf{B}$ and $\mathbf{C})$. Data represent mean \pm SEM.

At the other end of the spectrum, mice on the low-iron diet have low leptin. Although these mice maintain normal blood hemoglobin concentrations and are not overtly iron deficient, their hemoglobin concentrations are lower than animals on the higher-iron diets. Consistent with this observation, dietary iron supplementation in iron-deficient children results in increased growth and appetite (2). The normal association between leptin and body fat is also lost in the elderly, who are more likely to be effectively iron deficient $(17,45)$. Overall, these mouse and culture models accurately reflect not only the broad range of normal physiology, but pathologic human tissue iron levels as well.

Adipose tissue is a tissue with high heterogeneity. The pattern of fat distribution, truncal as compared with peripheral, has a profound influence on systemic metabolism and, hence, risk for metabolic diseases. Leptin is a well-known adipokine, regulating metabolism and energy homeostasis, and it is also believed that adipocytes from different anatomical depots are intrinsically different from each other and have different adipokine secretion capacity $(46,47)$. Thus, we used a mouse model with whole-body leptin expression monitored after different dietary iron intakes in order to demonstrate the effect in a fat depot-specific manner. The luciferase mouse data further support the conclusion that dietary iron modulation affects leptin at the levels of specific tissues, as well as the whole body.

In our study, we also found significantly increased food intake in high-iron dietary WT mice; however, this high-iron induced appetite is abolished in $o b / o b$ mice. If iron status directly regulates appetite at the central level, such as affecting hypothalamic neurons, we would expect to see similar phenomena in $o b / o b$ mice. Therefore, these results indicate iron may regulate appetite in a leptin-dependent manner, but not through central-level modulation. In addition, the decrease of leptin with high iron was not due to cytotoxicity and does not appear to be a simple result of oxidative stress (NAC along FAC treatment data in complete unedited blots in the Supplemental Material). Namely, even the highest dosages of iron did not affect cell viability, and antioxidant treatment did not rescue the downregulation of leptin by iron. Furthermore - consistent with published data (9) - the expression of another adipokine, resistin, increased in high iron (data not shown), which is not consistent with iron's effects being due to cytotoxicity.

The molecular mechanism for the regulation of leptin by iron includes phosphorylation of CREB. Besides iron, CREB is another well-known factor that can change fuel utilization from glucose to fat burning in mammals under fasting. Leptin is responsive to nutritional status, and fasting leads to a gradual decline in leptin $(48,49)$. CREB activation under fasting may play a role in diminishing leptin expression, and the cellular mechanism that causes leptin to fall with iron may be similar to that seen with fasting. Fasting evokes a number of responses, including an increase of glucagon, a known activator of CREB (50). Thus, CREB may play a role in connecting not only iron, but also macronutrient status to leptin. Prior to the current study, there was limited evidence for the regulation of leptin by CREB. It has been reported that activation of CREB during the differentiation process suppresses lep- 
tin secretion and expression in mesenchymal stem cell (51), and bioinformatics analysis indicates there are 2 potential CRE sites in the human ob promoter, but no study of their function has been reported (32). Interestingly, we have found that another nutrientsensing pathway, the hexosamine biosynthesis pathway (HBP), which is also known to play a crucial role in regulation of CREB (52) and has been reported to regulate leptin expression (53), also contributes to iron-induced changes in leptin expression. Namely, increased phosphorylation of CREB is associated with a decrease of O-GlcNAcylation of CREB, and activation of the HBP by glucosamine overcomes the iron-induced inhibition of leptin (data not shown, Yan Gao, unpublished data). Thus, reciprocal interplay of starvation (CREB) and overfeeding (HBP) pathways modulate leptin expression in an iron-responsive manner. These observations further underline the close relationship of iron levels with overall nutritional status and metabolic regulation.

In sum, the current results demonstrate that adipocytes serve to integrate not only the macronutrient status, but also the iron status of the organism to modulate metabolism, appetite, and energy homeostasis. Presumably, this would help maintain food-seeking behavior in an iron-rich environment that would support high rates of oxidative metabolism, energy production, growth, and reproduction.

\section{Methods}

Experimental animals. Dietary iron manipulations were accomplished with diets containing $60 \%$ carbohydrate, $17.7 \%$ protein, and $7.2 \%$ fat by weight (Harlan Teklad), and either $4 \mathrm{mg} / \mathrm{kg}$ (TD. 10210), $35 \mathrm{mg} /$ $\mathrm{kg}$ (TD. 10211), $500 \mathrm{mg} / \mathrm{kg}$ (TD. 10212), or 2,000 mg/kg iron (TD. 10214) for a period of 2 months before phenotyping. Mice were put on a diet around 3 months old. WT mice were of the C57BL6/J strain, and only male mice were used. In addition, mice with targeted deletion of the Hfe gene were studied after being bred onto the 129/SvEvTac genetic backgrounds for at least 5 generations (54). Mice with adipocyte-specific deletion of the ferroportin gene were generated by breeding mice with LoxP sites flanking exon 6 and 7 of the ferroportin gene (24) (provided by Nancy C. Andrews, Duke University, Durham, North Carolina, USA), with C57BL6/J mice containing an ap2 promoter-driven Cre recombinase (The Jackson Laboratory). Age- and sex-matched WT littermates were used as controls. Body composition analysis was performed using nuclear magnetic resonance system (Minispec LF50 BCA-Analyzer, Bruker). Transgenic mice expressing the luciferase reporter gene under the control of leptin regulatory sequences were provided by Jeffry M. Friedman (55).

Human subjects. The subjects were part of a larger study and were described previously (16). Their samples were deidentified for this study. Diabetes status was confirmed by oral glucose tolerance testing (OGTT). Diabetic subjects were on diet therapy only, with fasting plasma glucose between $125 \mathrm{mg} / \mathrm{dl}$ and $175 \mathrm{mg} / \mathrm{dl}$. All sera were obtained after a 12-hour overnight fast.

Reagents and assays. Reagents were purchased from SigmaAldrich unless otherwise noted. Serum leptin levels were measured by ELISA kit (Millipore). Serum ferritin and iron were measured by ARUP laboratories.

In vivo imaging. In vivo imaging of leptin/luciferase transgenic animals was performed using the Xenogen IVIS Lumina II imaging system (PerkinElmer). Because of the heterogeneity in the weights of the transgenic mice and the effect of weight on leptin, firefly levels were determined only in weight-matched mice. Isoflurane-anesthetized animals were injected i.p. with luciferin $(300 \mu \mathrm{l}$ of $15 \mathrm{mg} / \mathrm{ml}$ in PBS). The animals were imaged in an imaging chamber 15 minutes after injection, and the photon image was analyzed by Living Image 3.0 software (PerkinElmer) (55).

3T3-L1 adipocyte culture and differentiation. 3T3-L1 adipocytes (ATCC) were maintained in high-glucose DMEM (HG-DMEM) supplemented with $10 \%$ bovine calf serum (BCS, HyClone) and penicillin/streptomycin (Invitrogen). For differentiation (56), cells were incubated in HG-DMEM with $10 \%$ BCS for 48 hours after confluence. Cells were then cultured in differentiation medium I (HG-DMEM, $10 \% \mathrm{FBS}, 1 \mu \mathrm{g} / \mathrm{ml}$ insulin, $0.25 \mu \mathrm{g} / \mathrm{ml}$ dexamethasone, $0.5 \mathrm{mM} \mathrm{IBMX}$, and $4 \mu \mathrm{M}$ ciglitazone) for 4 days, followed by differentiation medium II (HG-DMEM, 10\% FBS, and $1 \mu \mathrm{g} / \mathrm{ml}$ insulin) for 48 hours. Prior to experiments, cells were cultured overnight in DMEM (Invitrogen) with $0.5 \%$ BSA. All experiments were performed in MEM- $\alpha$ medium, which is iron free, supplemented with $10 \%$ FBS and FAC, as indicated.

Plasmids, nucleofection, and luciferase assay. The approximately 6-kb (5,986 bp) and 764-bp 5'-flanking region of the murine leptin promoters were amplified with BglII-overhung or HindIII-overhung primers from genomic epididymal fat pad DNA and inserted into the pGL4.14 vector (Promega). Site-specific mutagenesis studies were carried out using QuikChange Lightning Multi Site-Directed Mutagenesis Kit (Agilent Technologies). Plasmids were nucleofected into undifferentiated 3T3L1 preadipocytes using the Nucleofector electroperator device (Nucleofector II AAD-1001N, device no. 400414, Amaxa Biosystems) with the Amaxa Cell Line Nucleofector Kit V (Lonza). After overnight incubation, positively transfected cells were selected by hygromycin. After 2 weeks' selection, pools of cells were differentiated and also used to select clonal cell lines. Luciferase activity was quantified using the Luciferase Reporter Assay System (Promega) and a 96-well plate luminometer. Luciferase levels of specific genes were normalized to protein levels.

Isolation of primary adipocytes. Fat pads (s.c. and epididymal) were removed from C57BL/6 male mice and incubated in HBSS with $1 \%$ BSA and $1.5 \mathrm{mg} / \mathrm{ml}$ collagenase, type I, for 45 minutes at $37^{\circ} \mathrm{C}$, rotating at 180 $\mathrm{rpm}$. Adipocytes were filtered through $100-\mu \mathrm{m}$ nylon mesh and rinsed with HBSS-1\% BSA. Following centrifugation at $880 \mathrm{rpm}$, the fat cake was transferred to a clean tube, rinsed, and centrifuged. Isolated adipocytes were either used immediately or flash frozen in liquid nitrogen.

Quantification of transcripts. Quantitative PCR (qPCR) was performed as described previously (57). Briefly, mRNA was extracted from primary or 3T3-L1 adipocytes or fat pad using TRIzol (Invitrogen), purified using an RNeasy column (QIAGEN), and synthesized into cDNA using a First-Strand cDNA Synthesis Kit (Invitrogen). The fat cake in TRIzol was cleared by transferring the infranatant to a clean tube using a glass syringe before extraction. qPCR was performed with a QuantStudio Real-Time PCR Systems (Applied Biosystems). cDNA products were quantified using the relative standard curve method. mRNA levels of specific genes were normalized to cyclophilin A or RPL13A.

Antibodies. Antibodies used included p-CREB (Ser 133) (87G3) and CREB (86B10) from Cell Signaling Technology, ob (A20, sc842) from Santa Cruz Biotechnology Inc., and $\alpha$-tubulin (T9026) from Sigma-Aldrich.

EMSA. Oligonucleotides were end-labeled with biotin. Differentiated 3T3-L1 adipocyte nuclear extracts were prepared using a nuclear extraction kit (ab113474, Abcam). The binding reaction was 
done according to the LightShift Chemiluminescent kit manual with some modification (20148, Fisher Scientific). Briefly, nuclear extract was added to binding buffer containing $5 \mathrm{nM} \mathrm{MgCl} 2,0.05 \% \mathrm{NP}-40$, $50 \mathrm{ng} / \mu \mathrm{l}$ poly $(\mathrm{dI}-\mathrm{dC})$, and $2.5 \%$ glycerol. It was incubated at room temperature for 10 minutes, with biotinylated oligonucleotide probe added, and incubated 25 minutes at room temperature. Protein-DNA complexes were resolved on $5 \%$ nondenaturing polyacrylamide gels and visualized by chemiluminescent nucleic acid detection module (89880, Fisher Scientific). For DNA competition, EMSA, nonbiotinylated WT, or mutant oligonucleotides were added first.

ChIP. ChIP studies were performed as described with minor modification (58). Chromatin was extracted from 3T3-L1 adipocytes on day 10-13 after differentiation using the SimpleChIP kit (9002, Cell Signaling Technology) according to the manufacturer's instructions. Briefly, cells were treated with $100 \mu \mathrm{g} / \mathrm{ml}$ of FAC for 24 hours prior to cross-linking for 10 minutes with $1 \%$ formaldehyde. Cells were then lysed by micrococcal nuclease and sonicated 3 times for 20 seconds using a sonic dismembrator (Fisher Scientific). p-CREB was then immunoprecipitated from precleared lysates with Protein A/salmon sperm DNA agarose beads (Millipore). DNA was released from protein-DNA complexes by proteinase $\mathrm{K}$ digestion, and then subjected to qPCR using power SYBR green kit (Applied Biosystems). The following primers, forward: 5'-GCA CGA TGT AAC CAC GAA TG-3' and reverse: 5'-ACG TCC ATT CAG CAA AAA CC-3', were used to amplify the CRE-1 site. Forward: 5'-GGC GAA AGG CAA ACA TAA GA-3' and reverse: $5^{\prime}$-TTC CCG CTC TGA CAT TCT TT-3' primers were used to amplify the CRE-2 site. ChIP-qPCR data were normalized for amount of chromatin by input samples and normal IgG samples.

Food intake measurement. Food intake was measured over a 3-day period with the Comprehensive Laboratory Animal Monitoring System (CLAMS; Columbus Instruments) using a 4-chamber opencircuit system. Animals were acclimatized to the chambers overnight prior to data collection and maintained at $24^{\circ} \mathrm{C}$ under a 12:12-hour light-dark cycle. Mice were housed individually with food and water freely available. Four mice were measured simultaneously. Food consumption was monitored by electronic scale for each mouse, and each cage was sampled for 1.5 minutes at 15 -minute intervals. Accumulated food intake was the sum of all acquired points.
Statistics. Descriptive statistics in the text and figures are represented as average \pm SEM. The Pearson's correlation coefficient was calculated to test for correlation between 2 parameters. Multivariate logistic regression analysis using STATA was sequentially performed to investigate the role of CRP, BMI, diabetes, and sex on the ferritinleptin association. An unpaired 2-tailed Student's $t$ test was used to determine significance between controls and individual experimental groups, except indicated. A paired 2-tailed Student's $t$ test was used to determine significance between controls and individual experimental groups in leptin-luciferase mice. One-way ANOVA was used to compare series of data. ${ }^{*} P<0.05,{ }^{* *} P<0.01$, and ${ }^{* *} P<0.001$ were considered significant.

Study approval. Animal studies were approved by the Institutional Animal Care and Use Committee of the University of Utah, under IACUC approval A3031-01. The human studies were approved by the IRB of the University of Utah, protocols 0880 and 20094. Studies were also reviewed and approved by the Advisory Committee to the Clinical Services Core (CSC) of the Center for Clinical and Translational Science. Additional previously unpublished data were from human studies completed at the Pennington Biomedical Research Center and at the University of Utah. Both studies were approved by the IRBs of the respective institutions, as previously published $(16,59)$.

\section{Acknowledgments}

This work was supported by the Research Service of the Department of Veterans Affairs (5IOBX001140) and the NIH (1R01 DK081842). W.T. Cefalu is also supported in part by NIH grant 1U54 GM104940 which funds the Louisiana Clinical and Translational Science Center and NIH grant P5OAT002776. We certify that there is no conflict of interest with any financial organization regarding the material described in this manuscript for any of the authors. Donald McClain is the guarantor of this work and, as such, had full access to all the data in the study and takes responsibility for the integrity of the data and the accuracy of the data analysis.

Address correspondence to: Donald A. McClain, Director, Center on Diabetes, Obesity and Metabolism, Wake Forest University School of Medicine, 1 Medical Center Blvd., Bldg NRC, Floor E, Winston Salem, North Carolina 27157, USA. Phone: 336.713.7233; E-mail: dmcclain@wakehealth.edu.
1. Lynch SR. Why nutritional iron deficiency persists as a worldwide problem. J Nutr. 2011;141(4):763S-768S.

2. Lawless JW, Latham MC, Stephenson LS, Kinoti SN, Pertet AM. Iron supplementation improves appetite and growth in anemic Kenyan primary school children. J Nutr. 1994;124(5):645-654.

3. Stoltzfus RJ, et al. Low dose daily iron supplementation improves iron status and appetite but not anemia, whereas quarterly anthelminthic treatment improves growth, appetite and anemia in Zanzibari preschool children. J Nutr. 2004;134(2):348-356.

4. Seltzer CC, Mayer J. Serum iron and iron-binding capacity in adolescents. II. comparison of obese and nonobese subjects. Am J Clin Nutr. 1963;13:354-361.

5. Gillum RF. Association of serum ferritin and indices of body fat distribution and obesity in Mexican American men - the Third National
Health and Nutrition Examination Survey. Int Obes Relat Metab Disord. 2001;25(5):639-645.

6. Moayeri H, Bidad K, Zadhoush S, Gholami N, Anari S. Increasing prevalence of iron deficiency in overweight and obese children and adolescents (Tehran Adolescent Obesity Study). Eur J Pediatr. 2006;165(11):813-814.

7. Nead KG, Halterman JS, Kaczorowski JM, Auinger P, Weitzman M. Overweight children and adolescents: a risk group for iron deficiency. Pediatrics. 2004;114(1):104-108.

8. Pinhas-Hamiel O, Newfield RS, Koren I, Agmon A, Lilos P, Phillip M. Greater prevalence of iron deficiency in overweight and obese children and adolescents. Int JObes Relat Metab Disord. 2003;27(3):416-418.

9. Dongiovanni $\mathrm{P}$, et al. Dietary iron overload induces visceral adipose tissue insulin resistance. Am J Pathol. 2013;182(6):2254-2263.

10. Shahramian I, Akhlaghi E, Ramezani A, Rezaee
A, Noori N, Sharafi E. A study of leptin serum concentrations in patients with major beta-thalassemia. Iran J Ped Hematol Oncol. 2013;3(2):59-63.

11. Karachaliou F, Vlachopapadopoulou E, Theochari M, Konstandellou E, Michalados S. Leptin levels in patients with thalassemia major. Minerva Pediatr. 2006;58(4):373-378.

12. Choobineh $\mathrm{H}$, et al. Evaluation of leptin levels in major beta-thalassemic patients. Int J Hematol Oncol Stem Cell Res. 2009;3(4):1-4.

13. Miraglia Del Giudice E, et al. Evaluation of leptin protein levels in patients with Cooley's anaemia. Br J Haematol. 1999;105(3):839-840.

14. Dedoussis GV, Kyrtsonis MC, Andrikopoulos NE, Voskaridou E, Loutradis A. Inverse correlation of plasma leptin and soluble transferrin receptor levels in $\beta$-thalassemia patients. Ann Hematol. 2002;81(9):543-547.

15. Topaloglu AK, Hallioglu O, Canim A, Duzovali O, Yilgor E. Lack of association between plasma 
leptin levels and appetite in children with iron deficiency. Nutrition. 2001;17(7-8):657-659.

16. Stull AJ, Galgani JE, Johnson WD, Cefalu WT. The contribution of race and diabetes status to metabolic flexibility in humans. Metabolism. 2010;59(9):1358-1364.

17. Fleming DJ, et al. Iron status of the free-living, elderly Framingham Heart Study cohort: an iron-replete population with a high prevalence of elevated iron stores. Am JClin Nutr. 2001;73(3):638-646.

18. Nelson R, Chawla M, Connolly P, LaPorte J. Ferritin as an index of bone marrow iron stores. South Med J.1978;71(12):1482-1484.

19. Cook JD, Lipschitz DA, Miles LE, Finch CA. Serum ferritin as a measure of iron stores in normal subjects. Am JClin Nutr. 1974;27(7):681-687.

20. Gabrielsen JS, et al. Adipocyte iron regulates adiponectin and insulin sensitivity. JClin Invest. 2012;122(10):3529-3540.

21. Wilson C. Metabolism: iron metabolism, adiponectin and T2DM - the link with adipocyte insulin resistance. Nat Rev Endocrinol. 2012;8(12):696

22. Milman N, Graudal N, Hegnhoj J, Christoffersen P, Pedersen NS. Relationships among serum iron status markers, chemical and histochemical liver iron content in 117 patients with alcoholic and non-alcoholic hepatic disease. Hepatogastroenterology. 1994;41(1):20-24.

23. Casey JL, et al. Iron-responsive elements: regulatory RNA sequences that control mRNA levels and translation. Science. 1988;240(4854):924-928.

24. Donovan A, et al. The iron exporter ferroportin/ Slc40a1 is essential for iron homeostasis. Cell Metab. 2005;1(3):191-200.

25. Eguchi J, et al. Transcriptional control of adipose lipid handling by IRF4. Cell Metab. 2011;13(3):249-259.

26. Furuhashi M, Fucho R, Gorgun CZ, Tuncman G, Cao H, Hotamisligil GS. Adipocyte/macrophage fatty acid-binding proteins contribute to metabolic deterioration through actions in both macrophages and adipocytes in mice. JClin Invest. 2008;118(7):2640-2650.

27. $\mathrm{He} \mathrm{W}$, et al. Adipose-specific peroxisome proliferator-activated receptor gamma knockout causes insulin resistance in fat and liver but not in muscle. Proc Natl Acad Sci U S A. 2003;100(26):15712-15717.

28. Cole BK, Morris MA, Grzesik WJ, Leone KA, Nadler JL. Adipose tissue-specific deletion of 12/15-lipoxygenase protects mice from the consequences of a high-fat diet. Mediators Inflamm. 2012;2012:851798.

29. Ross CE, Muir WA, Alan BP, Graham RC, Kellermeyer RW. Hemochromatosis. Pathophysiologic and genetic considerations. Am JClin Pathol. 1975;63(2):179-191.
30. Cairo G, Recalcati S, Montosi G, Castrusini E, Conte D, Pietrangelo A. Inappropriately high iron regulatory protein activity in monocytes of patients with genetic hemochromatosis. Blood. 1997;89(7):2546-2553.

31. Zeigerer A, Rodeheffer MS, McGraw TE, Friedman JM. Insulin regulates leptin secretion from 3T3-L1 adipocytes by a PI 3 kinase independent mechanism. Exp Cell Res. 2008;314(11-12):2249-2256.

32. Gong DW, Bi S, Pratley RE, Weintraub BD. Genomic structure and promoter analysis of the human obese gene. J Biol Chem. 1996;271(8):3971-3974.

33. Ahn S, Olive M, Aggarwal S, Krylov D, Ginty DD, Vinson C. A dominant-negative inhibitor of CREB reveals that it is a general mediator of stimulus-dependent transcription of c-fos. Mol Cell Biol.1998;18(2):967-977.

34. Sassone-Corsi P, Ransone LJ, Verma IM. Crosstalk in signal transduction: TPA-inducible factor jun/AP-1 activates cAMP-responsive enhancer elements. Oncogene. 1990;5(3):427-431.

35. Hai T, Curran T. Cross-family dimerization of transcription factors Fos/Jun and ATF/CREB alters DNA binding specificity. Proc Natl Acad Sci U S A. 1991;88(9):3720-3724.

36. Manna PR, Stocco DM. Crosstalk of CREB and Fos/Jun on a single cis-element: transcriptional repression of the steroidogenic acute regulatory protein gene. J Mol Endocrinol. 2007;39(4):261-277.

37. Fink JS, Verhave M, Kasper S, Tsukada T, Mandel G, Goodman RH. The CGTCA sequence motif is essential for biological activity of the vasoactive intestinal peptide gene cAMPregulated enhancer. Proc Natl Acad Sci U S A. 1988;85(18):6662-6666.

38. Sassone-Corsi P. Cyclic AMP induction of early adenovirus promoters involves sequences required for E1A trans-activation. Proc Natl Acad Sci U S A. 1988;85(19):7192-7196.

39. Nichols M, et al. Phosphorylation of CREB affects its binding to high and low affinity sites: implications for cAMP induced gene transcription. EMBO J. 1992;11(9):3337-3346.

40. Bothwell TH, Charlton RW. A general approach to the problems of iron deficiency and iron overload in the population at large. Semin Hematol. 1982;19(1):54-67.

41. Cook JD, Skikne BS, Lynch SR, Reusser ME. Estimates of iron sufficiency in the US population. Blood. 1986;68(3):726-731.

42. Farooqi IS, Bullmore E, Keogh J, Gillard J, O'Rahilly S, Fletcher PC. Leptin regulates striatal regions and human eating behavior. Science. 2007;317(5843):1355.

43. Friedman JM, Halaas JL. Leptin and the regulation of body weight in mammals. Nature. 1998;395(6704):763-770.

44. Simcox JA, et al. Dietary iron controls circadian hepatic glucose metabolism through heme synthesis. Diabetes. 2014;64(4):1108-1119.

45. Moller N, O'Brien P, Nair KS. Disruption of the relationship between fat content and leptin levels with aging in humans. JClin Endocrinol Metab. 1998;83(3):931-934.

46. Lee MJ, Wu Y, Fried SK. Adipose tissue heterogeneity: implication of depot differences in adipose tissue for obesity complications. Mol Aspects Med. 2013;34(1):1-11.

47. Hausman GJ, Hausman DB. Search for the preadipocyte progenitor cell. J Clin Invest. 2006;116(12):3103-3106

48. Fried SK, Ricci MR, Russell CD, Laferrere B. Regulation of leptin production in humans. J Nutr. 2000;130(12):3127S-3131S.

49. Wang J, Liu R, Hawkins M, Barzilai N, Rossetti L. A nutrient-sensing pathway regulates leptin gene expression in muscle and fat. Nature. 1998;393(6686):684-688.

50. Altarejos JY, Montminy M. CREB and the CRTC co-activators: sensors for hormonal and metabolic signals. Nat Rev Mol Cell Biol. 2011;12(3):141-151.

51. Yang DC, et al. cAMP/PKA regulates osteogenesis, adipogenesis and ratio of RANKL/OPG mRNA expression in mesenchymal stem cells by suppressing leptin. PLoS One. 2008;3(2):e1540.

52. Rexach JE, Clark PM, Mason DE, Neve RL, Peters EC, Hsieh-Wilson LC. Dynamic O-GlcNAc modification regulates CREB-mediated gene expression and memory formation. Nat Chem Biol. 2012;8(3):253-261.

53. McClain DA, et al. Altered glycan-dependent signaling induces insulin resistance and hyperleptinemia. Proc Natl Acad Sci U S A. 2002;99(16):10695-10699.

54. Zhou XY, et al. HFE gene knockout produces mouse model of hereditary hemochromatosis. Proc Natl Acad Sci U S A. 1998;95(5):2492-2497.

55. Birsoy K, et al. Cellular program controlling the recovery of adipose tissue mass: An in vivo imaging approach. Proc Natl Acad Sci U S A. 2008;105(35):12985-12990.

56. Chen Z, Torrens JI, Anand A, Spiegelman BM, Friedman JM. Krox20 stimulates adipogenesis via C/EBPbeta-dependent and -independent mechanisms. Cell Metab. 2005;1(2):93-106.

57. Huang J, et al. Increased glucose disposal and AMP-dependent kinase signaling in a mouse model of hemochromatosis. J Biol Chem. 2007;282(52):37501-37507.

58. Chakrabarti P, Kandror KV. FoxO1 controls insulin-dependent adipose triglyceride lipase (ATGL) expression and lipolysis in adipocytes. J Biol Chem. 2009;284(20):13296-13300.

59. Adams TD, et al. Health outcomes of gastric bypass patients compared to nonsurgical, nonintervened severely obese. Obesity (Silver Spring). 2010;18(1):121-130. 